\title{
Beyond History: A Legacy and a Vision
}

\author{
Leonor I. Cabral-Lim and Martesio C. Perez
}

Department of Neurosciences, College of Medicine and Philippine General Hospital, University of the Philippines Manila

\section{Introduction}

This work is a tribute to all those who have shaped the Department of Neurosciences of the National University Hospital and the University of the Philippines Health Sciences Center. I am deeply honored to have collaborated with my highly esteemed mentor and colleague, Dr. Martesio Perez, Professor Emeritus of the University.

History is more than a chronology of the past. There is much more beyond the names and events of the past. History has not only made us what we are today, but will also guide us to where we want to be in the future.

As the historian David McCullough stated, "History is an unending dialogue between the past and the present." This written history starts at the present, goes back in time, and moves forward toward our envisioned future.

\section{Where we are now}

The Department of Neurosciences is the clinical department of both the Philippine General Hospital (PGH) and the University of the Philippines College of Medicine.

It consists of the Sections of Adult Neurology, Neurosurgery and Pediatric Neurology with a complement of 66 medical personnel consisting of 36 consultants and 30 trainees. The Department's mission is to serve the Filipino people and advance the field of Neurosciences in the country by:

\begin{abstract}
providing excellent and compassionate neurologic and neurosurgical care; developing outstanding human health resources; mentoring future pioneering leaders and advocates through education, research, training, service, and advocacy.
\end{abstract}

Corresponding author: Leonor Cabral-Lim, MD, FPNA

Department of Neurosciences

College of Medicine

Philippine General Hospital

University of the Philippines Manila

Taft Avenue, Ermita, Manila 1000Philippines

Telefax No.: +632 5548462

Email: lcabral-lim@post.upm.edu.ph
In line with this mission, the Department's functions are grouped into 3 major areas:

\section{Service}

The PGH being the National University Hospital is a tertiary care hospital catering to all the complex cases referred from all over the country with an annual in patient admission of 45,092 patients of which 4,286 (9.3\%) are neurologic/neurosurgical cases. ${ }^{1,2}$ The hospital is primarily a service hospital that takes care of the poor segments of society.

$58 \%$ of the inpatient admissions are from the Charity Service, 55.2\%, $26.6 \%$ and 18.2.\% from the Sections of Adult Neurology, Neurosurgery and Pediatric Neurology, respectively. The top admissions are Stroke, Intracranial tumors, CNS infection, Epilepsy, Congenital Malformations and Traumatic head injury. The section of Neurosurgery performs 1012 operations/year. The most common neurosurgical operation is ventriculoperitoneal shunt insertion, followed by intracranial tumor excision and aneurysm surgery. ${ }^{2}$

The top most consult at the Outpatient Department is Epilepsy, for both the Adult and Pediatric Neurology Section comprising $40.92 \%$ and $76.6 \%$ of the patient visits, respectively, translating to a total of 5028 patient visits. This is followed by stroke and intracranial tumors. ${ }^{2}$

The department also sees a total of 2,589 interdepartmental referrals/year. ${ }^{2}$

\section{Training}

\section{A. Residency and Fellowship programs}

The department offers residency training programs in Adult Neurology and Neurosurgery graduating 5-6 residents and 2 pediatric neurology fellows/year. To date, the respective formal training programs of each section has graduated a total of 102 adult neurologists, 44 neurosurgeons and 22 pediatric neurologists. Majority of the graduates have become leaders, pioneers, educators and advocates in the Neurosciences irrespective of their place of practice. Many practice in the different regions of the country serving the needs of the community. Majority of those practicing in Metro Manila either has joined the department as members of the faculty or joined the academe in other institutions. 
The department also offers fellowship training programs in Clinical Epilepsy and Electroencephalography (EEG), and Electromyography and Clinical Neurophysiology.

\section{B. Undergraduate Education}

The Department is also tasked in implementing the undergraduate Neuroscience Curriculum of the UP College of Medicine consisting of 800 medical students/year from 1st year medical school to internship. The Neuroscience undergraduate Curriculum is integrated at all year levels of the medical curriculum and is a combination of didactics, small group discussions, ward preceptorships and actual supervised patient care both in the inpatient and outpatient settings. The department also offers undergraduate elective courses in the Neurosciences.

\section{Continuing Medical Education}

The Department holds the Annual "Neurology in Your Practice" postgraduate course which will be on its 12th year in 2015. The course is intended for neuroscience specialists, non-specialists and other health professionals to provide the latest updates and practical management issues in the Neurosciences.

The 3 Sections holds the following courses annually:

a. Adult Neurology - Epilepsy Scientific Symposium or Epilepsy Visiting Professor's Lecture

b. Neurosurgery-Visiting Professor's Lecture

c. Pediatric Neurology
i. Basic Neuroscience Course in Pediatric Neurology
ii. Seizure Management Workshop

\section{Research}

Over the last 5 years, 100 researches have been completed in the department. Most of these researches are primarily authored by the trainees and co-authored with the faculty and have been presented in local, regional and international conferences with some published locally. Members of the faculty also participate in national, regional and international researches in different capacities and these have been published locally and internationally. ${ }^{3}$

In line with the University's research thrust and to encourage a culture of research publication, trainees at the Section of Adult Neurology are now required to publish at least one original article in a peer-reviewed journal as a prerequisite for completion of the residency program.

In addition to its main functions, the department also has extension and advocacy programs which consist of:

A. Lead participation in the Celebration of National Epilepsy Awareness Week every 1st week of September each year, in cooperation with the Philippine League Against Epilepsy. This consists of a half- day lay symposium on epilepsy on various topics dealing with both the medical and social aspects of epilepsy. An epilepsy awareness and information multi- media booth is also set-up at the Philippine General Hospital during the entire week.

B. Participation in the Annual Neurology Week Celebration every 2nd week of November in cooperation with the Philippine Neurological Association

C. Celebration of Neuroscience Month in September Following the celebration of Epilepsy week, awareness and information booths are set-up for Stroke, Dementia, and Movement Disorders the rest of the month.

D. Epilepsy Education Program of the Section of Pediatric Neurology- epilepsy lay forums conducted quarterly and a yearly summer "epilepsy camp" for children with epilepsy, their parents and caregivers.

E. Faculty participation in the education, training and advocacy programs of the Philippine Neurological Association, Child Neurology Society of the Philippines, Philippine League Against Epilepsy, Stroke Society of the Philippines, Alzheimer's Disease Association of the Philippines, Dementia Society of the Philippines and Movement Disorders Society.

\section{How It All Began}

\section{Section of Adult Neurology}

The Beginning

The Philippine General Hospital (PGH) opened its doors to the public on Sept. 1, 1910 as the hospital for the Filipino people, a culmination of the efforts of the then Secretary of Interior Dean C. Worchester. The hospital's fundamental functions were: patient care, research and study of disease, clinical instruction for medical students of the Philippine Medical school (now UP College of Medicine) and training of young Filipino men and women as nurses. ${ }^{4}$

In keeping with increasing medical knowledge, the Department of Medicine has expanded into several specialties designed to better serve the increasingly complex needs of the people. One of the pressing needs then was a section dedicated to the specialized care and welfare of neuropsychiatric patients. ${ }^{5}$

Dr. Leopoldo Pardo Sr. was the first Filipino pensionado sent to the USA who had formal training in neuropsychiatry. He returned home from Harvard in 1930 and mainly taught at the UST but also came to the PGH to teach Neurology. ${ }^{6}$

Dr. Friedman, (a Viennese Jew running away from Hitler) was appointed as the first chief of the Section of Neuropsychiatry, Department of Medicine. He left after 2 
years and Dr. Marciano Limson became the reluctant second chief. Dr. Marciano Limson was the first Filipino to teach neuroanatomy, neurology, and psychiatry during the Commonwealth period. Dr. Limson, was a neuroanatomist who trained at John Hopkins and Minnesota, and was known as a "walking anatomy book". ${ }^{6}$

In 1956, Dr. Romeo Apostol headed the Section of Neuropsychiatry, teaching neurology while Psychiatry was handled by a visiting professor Dr. Howard Potter. Dr. Apostol was trained by the very brilliant Dr. Francis Forster, one of the founders of the American Academy of Neurology. ${ }^{6}$ Dr. Apostol passed away in 1960, after which there was a succession of neurologists who served the section: Dr. Faustino Domingo (1960-1962) and Dr. Teresita Elizan who wrote several papers on Parkinsonism and viruses in the nervous system, working with Dr. Melvin Yahr. Dr. Elizan only stayed from 1962-1963 and she was succeeded by Dr. Marina Mendoza (1963- 1965). In 1964, Psychiatry became an independent Department, headed by Dr. Baltazar V. Reyes Jr. with Neurology remaining as a Section in the Department of Medicine. Dr. Mendoza elected to stay with the section. ${ }^{6}$ Both Drs. Elizan and Mendoza subsequently migrated to the USA.

\section{The early years}

Dr. Martesio Perez first joined the Section of Neurology in 1965 as chief of section after a 4-year stint as a China Medical Board scholar at the University of Wisconsin, Columbia Presbyterian Hospital in New York and research fellow in Epilepsy and muscle diseases under Dr. Eli Goldensohn and Dr Milton Shy at the University of Pennsylvania. At about the same time, Dr. Braulio Idea joined the section; 6 he trained at the University of Maryland. Subsequently, Drs. Alfredo Bengzon and Lillian Lee joined the section. ${ }^{6}$

Through the prodding of Dr. Perez, the then Chairman of the Department of Medicine, Dr. Paulo Campos acceded to the establishment of a formal Neurology residency training program at the section of Neurology in 1972. This started as a three-year program and was the first formal residency training in the country, initially accepting one resident trainee per year level.

Before the establishment of the formal Neurology residency training program, Drs. Cora Rivera and Gloria Lopez rotated in a clinical preceptorship program at PGH for two years. They were the first informally trained residents at the section. ${ }^{6}$

Dr. Idea stayed as a member of the faculty until his untimely demise in 1977.

Dr. Alfredo Bengzon trained at the University of Wisconsin and later at the Montreal Neurological Institute and remained in the faculty until he was appointed Secretary of Health under the President Corazon Aquino administration.
Dr. Lillian Lee trained in adult Neurology at the Wayne State University in Michigan, USA and took her postresidency fellowship in pediatric neurology in Chapel Hill, North Carolina under Dr. Thomas Farmer. She succeeded Dr. Martesio Perez as Section Chief in 1974. She subsequently transferred to the Lungsod ng Kabataan (now known as the Philippine Children's Medical Center (PCMC)) in 1982. In 1986, she was appointed Executive Director of PCMC. On the same year, she established the Child Neuroscience Department in that institution and the first formal child neurology fellowship program in the Philippines with her as program director and Dr. Aida Salonga as the training officer.

The first resident and graduate of the formal adult neurology training program was Dr. Rogelio Libarnes. He was initially a resident in Internal Medicine who was convinced by Dr. Paulo Campos to transfer to the Section of Neurology when the Adult Neurology training program was started. On his last year of training, he was sent to the University of Oslo in Norway. After completion of his training program at the Section of Neurology, Dr. Libarnes joined the private practice of Dr. Perez for one year. Subsequently, he pursued further training in Neuroophthalmology at the University of New Mexico Albuquerque, New Mexico, USA and joined the consultant staff of the Section of Neurology upon his return to the Philippines. Subsequent graduates of the Section of Neurology training program who joined the consultant staff were Drs. Fe Enrile-Bacsal, Faith Fuentes, Elizabeth ZaraspeYoo and Regina Macalintal-Canlas.

Dr. Fe Bacsal was the first Adult Epileptologist and Electroencephalographer in the Section. She trained under Dr. Antonio Escueta at the University of California Reed Neurological Research Center and VA Wadsworth Medical Center in Los Angeles, California from 1979-1981. Dr. Regina Macalintal-Canlas trained in Neuropathology and Headache under Professors James Lance and Kakulas at the Prince Henry Hospital, New South Wales, Australia. Drs. Libarnes, Bacsal and Macalintal-Canlas stayed as members of the consultant staff sharing their expertise, until their retirement. Drs. Zaraspe-Yoo and Faith Fuentes have migrated to the USA.

Dr. Zenaida Bagabaldo, from the Department of Physiology, had her Physiology training at the Temple University School of Medicine in Philadelphia, USA under Prof. Morton J. Oppenheimer from 1958-1959. She took her Master of Science in Physiology (M.Sc.) at the Institute of Physiology, University College London, University of London from 1963-1965 under the Colombo Plan. She was Chairman of the Department of Physiology of the University from 1975-1985. She handled the Basic Neurophysiology sessions with the neurology residents from 1977 until her retirement. At the same time, she took a clinical rotation at the Section of Neurology for three months and went into a 
clinical preceptorship in Neurology under Dr. Martesio Perez for three and a half years.

Dr. Bagabaldo was the first electromyographer and clinical neurophysiologist in the section having performed the first electromyography procedure in the Philippines, using a machine assembled from component parts consisting of a stimulator, pre-amplifier, amplifier and computer display; initially intended for research purposes. Thereafter, an electromyography/clinical neurophysiology rotation was included in the residency program. Following her retirement in 1993, she was appointed as Emeritus Professor in the University.

In 1977, Dr. Nestor Bautista, a neuroanatomist from the Department of Anatomy and Drs. Jaime Zamuco and Ernesto de Veyra, both neuropathologists from the Department of Pathology handled the neuroanatomy and neuropathology sessions with the resident trainees until the time of their retirement.

In 1979, then UP College of Medicine Dean Gloria Aragon created the Neuroscience Committee to study the possibility of applying the problem oriented method of teaching. The Neuroscience Committee was composed of the Section of Neurology (Dr. Martesio Perez), section of Neurosurgery (Dr. Faustino Domingo), Department of Pediatrics (Dr. Aida Salonga) and the Departments of Anatomy (Dr. Nestor Bautista) and Physiology (Dr. Zenaida Bagabaldo) of the College of Medicine. The committee's recommendations were first applied to the neurosciences, thus the first Integrated Neuroscience course was started in 1984. This was the first medical course to be integrated both vertically and horizontally and served as the model to the present integrated courses at the UP College of Medicine. The course introduced the medical students to the neurology wards through actual history taking and neurologic examination in their first year of medical education.

\section{Continued Growth}

The decade of the 80's marked the return of committed local Adult Neurology graduates who returned to the country following their post-residency training abroad, strengthening and further developing the section.

Dr. Leonor Cabral-Lim (Adult epileptology, Electroencephalography and Evoked potentials), Dr. Carlos Chua, (Neuromuscular disorders and Neuropathies), Dr. Philip Ramiro (Clinical Neurology and Headache), Dr. Ester Bitanga (Clinical Neurology) and Dr. Mayvelyn Gose (Electromyography and Evoked potentials).

Dr. Edmundo Saniel joined the Section in 1980 following his residency and fellowship training abroad (Electromyography, Clinical Neurophysiology and Neuromuscular disorders) and stayed up to 1983.

In 1981, Dr. Martesio Perez invited Dr. Lourdes Ledesma, the first formally trained Clinical
Neuropsychologist to join the Section. This provided the residents exposure to neuropsychological concepts and constructs which led some of them to undertake researches that included these. Dr. Ledesma has a doctorate in Counseling Psychology from Boston College, Massachusetts and had her training at the Department of Psychiatry, Harvard Medical School and at the Boston Children's and Boston Veteran's Administration Hospital where she was mentored by Drs. Natalie Sollee and Edith Kaplan, respectively.

Among the 1980 entrants to the faculty, majority are still serving the University and most have assumed administrative positions in the Department. Dr. Gose, like the rest of her contemporaries and most of her predecessors has dedicated most of her professional career to the Department, until she fell ill in February 1998. Dr. Ester Bitanga retired in November 2013; prior to her retirement she was Assistant Director for Health Operations of the PGH from January 2011 to Nov 2013.

In the 1990's, the following joined the faculty with their respective post-residency training: Dr. Marita Dantes (Electromyography and Clinical Neurophysiology), Dr. Carissa Dioquino, (Neurotoxicology), Dr. Josephine Casanova-Gutierrez, (Neuroimmunology), Dr. Grace Orteza (Neuroinfectious Immunology), Dr. Robert Gan (Stroke and Cerebrovascular Disease), and Dr. Paul Pasco (Neurogenetics). Dr. Dioquino later obtained a Masters in Public Health (Occupational and Environmental Health) from the Harvard School of Public Health in Boston, Massachusetts. She is currently Head of the National Poison Management and Control Center, UP Manila. Dr. Gutierrez pursued a fellowship in Clinical Epileptology and Electroencephalography at the New South Wales, Prince of Wales Hospital, Sydney, Australia. Dr. Pasco subsequently obtained a Masters Degree in Clinical Epidemiology from the UP College of Medicine. Drs. Dioquino, Gutierrez and Pasco have remained in the section.

\section{Fellowship Training Programs}

\section{Clinical Epilepsy and Electroencephalography}

The Clinical Epilepsy and Electroencephalography (EEG) fellowship training program was started in 2003 with Dr. Bernadette Terencio as the first graduate. Her mentors included Drs. Fe Bacsal, Leonor Cabral-Lim, Josephine Casanova-Gutierrez, Conrad Nievera and Benilda SanchezGan.

\section{Electromyography and Clinical Neurophysiology}

The fellowship program in Electromyography and Clinical Neurophysiology was started in 1997 under the mentorship of Drs. Marita Dantes and Zenaida Bagabaldo. The first graduate of the program was Dr. Arturo Surdilla. 


\section{Section of Neurosurgery}

\section{The Beginning}

Before the Second World War, the practice of neurosurgery was mostly confined to trauma cases and was in the hands of general surgeons. The first craniotomy in the Philippines (for the evacuation of a subdural haematoma) was performed in 1928 at the PGH by Jose Abuel who studied neurosurgery at Harvard from 1923 to 1925. Abuel brought home the technique of pneumoencephalography for localizing intracranial lesions. Andres Zavalla, another general surgeon, went to Johns Hopkins Hospital in Baltimore during the 1930's to train under Walter Dandy. Zavalla did the first craniotomy for the excision of a brain tumour in the country in $1941.7,8$

Victor A. Reyes, a surgical resident under Zavalla, went to the United States and Canada in 1947. He underwent five years of training in neurosurgery with Michael Scott Sr. at University of Pennsylvania, Gilbert Horrax at Lahey Clinic in Boston, Wilder Penfield et al. at the Montreal Neurological Institute in Canada. He was the first Asian to be certified by the American Board of Neurological Surgery in 1951. Reyes started the neurosurgery service at the Philippine General Hospital upon his return to the Philippines in 1952. ${ }^{7,8}$

Dr. Faustino Domingo, Jr. was trained by Dr. Victor Reyes. ${ }^{6}$ In 1959, he finished as the first locally trained neurosurgeon in the Philippines. He later took up a residency training in Neurology at the University of Wisconsin with Dr. Francis Forster. A year after, he moved on to the Lahey Clinic under Dr. James Poppen.6,8 When he returned in 1961, the Reyes-Domingo tandem became "the" section of Neurosurgery. ${ }^{8}$

In the 1960's, Dr. Mariano Torres and Dr. Leopoldo Pardo, (the son of Dr. Leopoldo Pardo Sr.) joined the section of Neurosurgery. Dr. Torres died early in his career. Dr. Pardo trained at Baylor University and he is credited to have done the first transsphenoidal surgery for pituitary adenoma in the country. ${ }^{8}$ He left for the US in 1972 after the declaration of Martial Law but came back in 1994 to rejoin the Division of Neurosurgery, Department of Surgery as a Clinical Associate Professor. He retired in 1995 upon reaching the mandatory age of retirement of 65 .

\section{The early years}

The first formal Residency Training Program in Neurosurgery in the Philippines was established at the Philippine General Hospital in 1976, with the Neurosurgery service becoming the Division of Neurosurgery of the Department of Surgery. The mentors included Dr. Roel Romero as the Division Chief, with Drs. Ramon Suter, Renato Sibayan, Victor Reyes, and Faustino Domingo, Jr. in the Faculty. Dr. Camellia Posoncuy later joined the staff upon her return from Switzerland in 1979. The first graduates of the program included Drs. Norman Bitanga and Antonio
Rafael. They were followed by Dr. Ferdinand Florendo, and later on, Drs. Willy Lopez and Antonio Amor. Drs. Roel Romero Ramon Suter and Dr. Sibayan stayed as members of the division until 1980.

\section{Continued Growth}

Neurosurgery continued to build up its teaching staff from the many graduates of the residency training program:

Dr. Norman Bitanga joined the Consultant Staff in 1983 after finishing a Fellowship in Pediatric Neurosurgery at the Sick Kids Hospital in University of Toronto System. Dr. Willy Lopez followed in 1986, after his Fellowship in Cerebrovascular Neurosurgery at Columbia University, Neurological Institute of New York.

Dr. Manuel Mariano joined the section from 1991-2001. He went into a preceptorship with Professor Pernezky of the University of Mainz in Germany in 1995 and introduced the concept of keyhole surgery and endoscopic neurosurgery to the Philippines. Subsequently, Dr. Gerardo Legaspi (1994) and Dr. Eric Legaspi (1996) were appointed after completing their fellowship in Pediatric Neurosurgery and Spine Surgery, respectively. In 1998, Dr. Annabell Chua joined the section, bringing with her skills acquired in fellowships in Neurotrauma and Epilepsy surgery.

Dr. Eduardo Mercado, a graduate of UP, finished his Residency training in Neurosurgery at Tufts University in Boston and joined the Staff of the Division of Neurosurgery at PGH from 1982 to 1986.

\section{Section of Pediatric Neurology}

\section{The beginning and early years}

In 1989, Dr. Aida Mendoza-Salonga initiated the creation of a formal Pediatric Neurology Post-Residency Fellowship Training Program at the PGH and became the first director of the program. This was a joint program of the Department of Pediatrics under the chairmanship of Dr. Amelia Fernandez, and the Section of Neurology of the Department of Medicine with Dr. Ester Bitanga then as Chief of Section. Dr. Salonga is a 1979 graduate of the residency training in Neurology of the Section of Neurology of the Department of Medicine. She pursued further training in pediatric neurology under the tutelage of Dr. Lillian Lee from 1980-1981 thru a grant from the China Medical Board.

Dr. Myrna S. Fojas, upon her return to the Philippines from her training at the University of New Jersey, served as the program's first training officer from 1990-1995. She left the Philippine General Hospital in 1996 but continues to help in providing the needs of the section for patient care. 
Dr. Marissa Lukban was the first graduate of the pediatric neurology fellowship program and continued her training at the Royal Alexandria Hospital for Children in Sydney, Australia and the New Children's Hospital in Westmead, Australia in 1994-1995. Upon her return, she served as the Section's training officer from 1996-2004 and section head from 2005 to 2012.

In 1999, with the Creation of the Department of Neurosciences, the faculty of the Section of Pediatric Neurology joined the Department of Neurosciences as crossappointees from the Department of Pediatrics.

\section{The creation of the Department of Neurosciences}

The Department of Neurosciences was created through a resolution of the Board of Regents of the University on the 30th day of September, 1999. The creation of the Department of Neurosciences merged three sections from three departments, namely the Sections of Adult Neurology, Neurosurgery and Pediatric Neurology in order to provide optimal care for neurological and neurosurgical patients. It also integrated and took under its wing the undergraduate and postgraduate training programs in the neurosciences.

The Section of Neurosurgery was completely integrated into the Department of Neurosciences in 2003. All the consultants, residents and nursing complement staff were organizationally transferred from the Department of Surgery to the Department of Neurosciences.

The Section of Pediatric Neurology is under two clinical departments at the Philippine General Hospital, the Department of Pediatrics, its home clinical department, and the Department of Neurosciences, as its home for the teaching of the Neuroscience Curriculum.

Faculty members from the Departments of Anatomy (Dr. Leonard Pascual V), Physiology (Dr. Darwin Dasig and Dr. Salome Nicdao Vios) and Pharmacology (Dr. Jose Paciano Reyes) primarily teach the basic Neuroscience Courses, with cross-appointments with the Department of Neurosciences.

Since its departmentalization, new members of the faculty have joined the consultant staff in the different sections, mostly with specific subspecialties:

Section of Adult Neurology: Dr. Artemio A. Roxas (Clinical Epidemiology), Dr. Godfrey Robeniol (Clinical Neurology), Drs. Jose Paciano Reyes and Ma. Geraldine Espiritu (Electromyography and Clinical neurophysiology), Drs. Cristina San Jose and Jose Leonard Pascual V ( Stroke and Cerebrovascular Diseases), Dr. Epifania Collantes (Neurointensive Care and Clinical Epidemiology), Drs. Conrad Nievera, Josephine Casanova Gutierrez and Katerina Tanya Perez-Gosiengfiao (Adult Epileptology and Electroencephalography), Dr. Julette Marie F. Batara (Neuro-oncology), Dr. Veeda Michelle Anlacan (dementia and cognitive impairment), Dr. Roland Dominic Jamora (Movement Disorders), and Dr. Mina Astejada (Neuromuscular Disorders).

Section of Neurosurgery: Dr. Peter Rivera (Endovascular Neurosurgery), Dr. Ibet Sih (Spine surgery), and Dr. Kathleen Khu (Peripheral Nerve Surgery and Neurosurgical Oncology).

Section of Pediatric Neurology: Dr. Benilda SanchezGan (pediatric epileptology), Dr. Marilyn Tan (pediatric Stroke), and Dr. Martha Lu-Bolanos (adult and pediatric clinical neurology).

All the above mentioned new members of the department are all graduates of the residency training program of the Department except for Drs. Gosiengfiao, Nievera and Dr. Benilda Sanchez-Gan. All went into further sub-specialty training abroad or locally and all are still active members of the department except for Dr. Nievera who has emigrated.

Dr. Martesio Perez became the First Chairman of the Department of Neurosciences. Upon his retirement in 2000, he was appointed as Professor Emeritus by the University. He was succeeded by Dr. Aida M. Salonga, from the Section of Pediatric Neurology. Dr. Salonga is currently the Director of the Institute of Child Health at the National Institute of Health, Manila.

Dr. Willy Lopez followed Dr. Aida Salonga. He was the first Chairman of the Department from the Section of Neurosurgery. Subsequent chairs were Drs. Philip Ramiro and Carlos Chua from the Section of Adult Neurology.

Dr. Leonor I. Cabral-Lim is the present chair of the Department of Neurosciences. She now takes the lead in the department's commitment of achieving its renewed Mission and Vision.

\section{Beyond History: A Legacy and a Vision}

For those who will read this now and in the future, the evolution of the Department of Neurosciences is just a chronology of names and events. But for those of us who are part of this history, every name and event evokes memories: of long hours being mentored by our teachers, of long hours teaching our students, of taking care of patients, enduring sleepless nights. We remember spending hours in the operating room and the outpatient department. We recall the joy of discovering and imparting knowledge, the joy of curing patients, and the frustration when we are unable to help them. Our predecessors and our contemporaries have dedicated most of our professional careers to this institution and have done our best the best way we can. We are confident that those who follow us will not only continue to do the same, but also do even better. There is a legacy 
beyond every name mentioned here, a legacy of service, excellence, leadership and compassion.

We have a roster of outstanding and committed health care professionals in our faculty and a pool of excellent human health resources among our trainees. There is a great potential for the development of the department into a center of excellence in the Neurosciences given the proper infrastructure, state of the art facilities and equipment and adequate funding. Such a center of excellence, envisioned as the Philippine Neuroscience Center is long overdue and should be a priority of government.

Let us continue the legacy of those before us while keeping the same passion and commitment. Let us focus on the strategies set towards what we want to achieve as stated in our vision:

"The internationally recognized center of excellence and leadership in Neuroscience education, research, training, service and advocacy dedicated to the Filipino people, especially for the underserved."

\section{The Filipino deserves no less.}

DISCLAIMER: The authors have exerted best efforts in the collection and accuracy of the historical data presented in this manuscript. Sources of information include publications, websites of relevant universities, files in the Department of Neurosciences and the University and primary and secondary interviews with all possible informants. Any gaps and inaccuracies are solely the responsibility of the authors. We welcome any and all comments.

\section{Acknowledgments}

We would like to acknowledge the contribution of the following members of the Department of Neurosciences for their invaluable contribution to filling the gaps and verifying the accuracy of the information provided in the historical part of this manuscript: Willy Lopez, MD, Philip Ramiro,MD, Aida Salonga,MD and Marissa Lukban, MD.

\section{References}

1. Philippine General Hospital Facts and Figures. Institutional Research, Planning and Development Staff. 2012. p. 9

2. Department of Neurosciences 2012 Annual Report. On file.

3. Department of Neurosciences Annual Reports 2008-2012.On file.

4. Snodgrass John E, Fox Carroll. History and description of the Philippine General Hospital, Manila, Philippine Islands 1900-1911. Bureau of Printing Manila, 1912 [Online]. [cited 2014 Jan]. Available from https://archive.org/details/cu31924063266534

5. UP-PGH Neurosciences History [Online]. [cited 2014 Jan]. Available from http://pghneuro.wordpress.com/about/history/

6. Perez M. History of Neurology in the Philippines. PJN. 2003; 7(1):1-7.

7. Asia and the World Federation of Neurosurgical Societies. pp. 209-210 [Online]. [cited 2014 Jan]. Available from http://www.wfns.org/filebin/history/Chapter4-3.pdf

8. Legaspi G. Neurosurgery at the Philippine General Hospital through decades of change.Journal of Philippine Neurological Surgery. Volume 3 \& 4, 2000. pp. 13-17. 